\title{
Os desafios da "escrita por encomenda" e o esforço de desmitificação no pensamento de Simone de Beauvoir*
}

Magda Guadalupe dos Santos**

\section{Resumo}

Neste artigo analiso a relação argumentativa de tópicos de $O$ Segundo Sexo, publicado em 1949, com os escritos "encomendados" por editores norte-americanos, como o texto intitulado Brigitte Bardot e a síndrome de Lolita, de agosto de 1959. O que há de comum entre eles é a proposta de desmitificação, presente nos escritos teóricos e nos nomeados autobiográficos. Sempre preocupada em perquirir temas de relevo, Beauvoir discute tópicos de simetria, de identidade e diferença, tanto entre culturas - da Europa às Américas -, quanto entre os sexos - na complexa relação do feminino, criticado em bases de suposta "natureza" das mulheres, e o masculino, que se destaca na sociedade patriarcal. Não se trata de reverter, pela escritura, os dilemas da história, mas de criticar o impacto da cultura na leitura e na escritura do real, sem jamais se resignar ao arbítrio e imposições. Indago, assim, sobre o teor axiológico que suscitam os escritos "encomendados"; se poderia ser também o mesmo que se configura em $O$ Segundo Sexo, em seu esforço de desmitificar as ilusões que sobrevoam a realidade histórica. Busco, na interação entre textos e práticas de vida, compreender $\mathrm{o}$ método de análise que lança o pensamento de Beauvoir como uma matriz dos feminismos contemporâneos.

Palavras-chave: Beauvoir, Escritos Encomendados, Desmitificação, Identidade e Diferença.

\footnotetext{
* Recebido em 15 de maio de 2019, aceito em 02 de outubro de 2019.

** Pesquisadora da Faculdade de Educação da Universidade do Estado de Minas Gerais (FaE. UEMG) e do Departamento de Filosofia e da Faculdade de Direito da Pontifícia Universidade Católica de Minas Gerais (PUC Minas), Belo Horizonte, MG, Brasil. magda.guadalupe@yahoo.com.br / https://orcid.org/00000001-6894-0654
} 


\section{Introdução}

A obra de Simone de Beauvoir tem sido recepcionada de várias perspectivas, possibilitando análises e interpretações diversificadas nas últimas décadas. No traçado de seus escritos, pode-se constatar uma variação de formas literárias e de métodos investigativos, com temáticas diversas, porém dialógicas. Busco, assim, neste artigo, alinhar algumas questões em função de métodos e argumentos, levando em consideração dois ensaios, Le Deuxième sexe (1949) e Brigitte Bardot and the Lolita Syndrom (1959). Para maior comodidade, cito os escritos com seus títulos nas edições brasileiras, algumas vezes fazendo referência à primeira edição em francês ou inglês.

Minha intenção é considerar, de um lado, certo recorte temático-metodológico dos ensaios sobre o feminino na cultura, que ganham projeções feministas nas análises de Beauvoir e em teorias e movimentos que se projetam em torno à Segunda Onda Feminista pós 1960, tanto nos EUA, quanto na França; de outro, interessa identificar possibilidades interpretativas atuais de comentadoras da obra beauvoiriana. Finalmente, pretendo estabelecer uma interlocução com os estudos, entre outros, de Karen Vintges (2002, 2017), de Debra Bergoffen $(2002,2012)$ e, especialmente, de Sylvie Le Bon de Beauvoir (2018), em torno de questões filosóficas e feministas.

Viso, sobretudo, examinar uma possível correspondência do "esforço de desmitificação", que, desde O Segundo Sexo, aparece nas intenções de Beauvoir, em ensaios, práticas e vivências, sempre em termos de princípios existencialistas. Conforme o entendimento de Sylvie Le Bon de Beauvoir, o termo "desmitificar" (démystifier) não corresponde exatamente, em Beauvoir, a "desencantar", mas evidencia uma intenção de revelar a prevalência de "falsos ídolos", assim como de "ilusões mortíferas" que encobrem o que a realidade tem de profundo $e$ belo (Le Bon de Beauvoir, 2018:34).

O tema da desmitificação foi tratado por Simone de Beauvoir em suas memórias, especialmente em Tout compte fait 
(1972), ou Balanço Final (1982). Nela Beauvoir menciona precisamente que "dissipar as mistificações (dissiper les mystifications), dizer a verdade (dire la vérité), eis um dos objetivos" por ela perseguido (Beauvoir, 1972:512; 1982:501). Nessa passagem, ela trata da recepção de seus escritos e das interpretações que variam conforme o entendimento dos leitores; por um lado, há opiniões que apreciam sua "tendência à felicidade" (mon goût du bonheur), por outro lado, aquelas que atestam "deplorar" o seu "pessimismo" (déplorent mon pessimisme) (Beauvoir, 1972:511; 1982:501).

O que Beauvoir propicia às leituras filosóficas corresponde a novas metodologias discursivas, que permitem repensar os obstáculos existenciais. Nesse sentido, ressalta certa provocação, seja interpretativa, seja axiológica, que repercute como um impacto existencialista adentrando a realidade vivida. Nos ensaios mencionados $e$ nas variações em torno às questões sobre o feminino na cultura, verifica-se diferença entre o propósito inicial de $O$ Segundo Sexo e do artigo sobre Brigitte Bardot, separados por uma década. Este segundo texto, de 1959, como ressalta Le Bon de Beauvoir (2018:21), é um exemplo de seus "escritos por encomenda", ou seja, textos publicados a convite de revistas $e$ jornais voltados para o público em geral. ${ }^{1}$

Uma apresentação singular

Importa considerar alguns pontos que aproximam os dois trabalhos e investigar se, nas formas de escritura, Simone de Beauvoir teria se esforçado no sentido de desmitificar as ilusões que sobrevoam a realidade e lhe imprimem o peso de "belas imagens", ou se, no esforço para satisfazer as encomendas, deixariam esses textos de ensejar novas possibilidades de crítica às ilusões e logros fabricados culturalmente.

\footnotetext{
1 Neste sentido, interessante comentar que a primeira edição de tais escritos aparece em inglês, publicada na revista Squire, e não em francês, como fora escrito originalmente por sua autora, conforme se analisa na terceira parte deste artigo.
} 
Variações sobre métodos e tópicos discursivos

O que parece implícito no texto de Le Bon em apresentação aos escritos traduzidos e publicados no Brasil, em 2018, explicitase na dinâmica da textualidade de várias obras da filósofa, surgindo com objetivo bem definido: a preocupação em sempre poder dizer algo livremente, provocando certa recepção e um efeito estético em leitores das várias partes do mundo.

Wolfgang Iser entende que "o texto é um potencial de efeitos, que somente pode ser atualizado no processo da leitura" (Iser, 1987:11). Ora, justamente essa parece ser uma das preocupações de Beauvoir. Ao investigar em Literatura $e$ Metafísica, ensaio publicado em Les Temps Modernes, em 1946, a tênue demarcação entre ficção e filosofia, ela escreve: "o romance não se reveste do seu valor e da sua dignidade se não se constituir para o autor, como para o leitor, uma descoberta viva" (Beauvoir, 2008:68). A interação com o leitor sempre foi para ela um tópico importante na estrutura argumentativa.

\section{A preocupação com o leitor}

Independentemente de qual o modelo de escritura e de suas fonte e origem, acredito que a intenção de Simone de Beauvoir sempre foi a de enfrentar os desafios da existência, sem subordinar-se às finalidades de seu editor, demonstrando grande preocupação com os leitores, os quais tomava como referencial, como se pode ler nos prólogos de suas obras de memória. No capítulo 1 de Balanço Final, ela escreve:

Objeta-se também que relatar é substituir a fluida ambiguidade do vivido (la fluide ambigüité du vécu) pelos contornos estáticos das frases escritas. Mas, na verdade, as imagens que as palavras sugerem são mutáveis e fluidas, o saber que comunicam não é claramente circunscrito. De toda maneira, não me proponho aqui conduzir o leitor através de um sonho desperto (de conduire le lecteur à travers un rêve éveillé) que ressuscitaria meu passado, mas 
sim examinar minha história de determinados conceitos $e$ noções (Beauvoir, TCF1972:13; BF1982:11).

Chama a atenção sua trajetória metodológica, conforme já analisei em outros textos (Santos, 2012), com bases axiológicas que sofrem variações no correr da escrita, por força de novos desvelamentos do mundo ao seu redor. Assim foi com $O$ Segundo Sexo que foi projetado inicialmente só como uma pesquisa sobre a mitologia acerca do feminino, acabando por transformar-se numa obra de relevo histórico-cultural que avança pelos tempos. Essa obra, conforme M. Luisa Femenías (2012), "não nasce da inclinação feminista de Simone de Beauvoir", mas de sua gradual percepção de que "habita um mundo alheio", e que é um mundo masculino, propriamente dito (Femenías, 2012:18). Um mundo em que o lugar da identidade e da simetria se transforma no lugar da alteridade.

\section{A transição epistemológica}

É importante relacionar o entendimento de Sylvie Le Bon de Beauvoir acerca do intento beauvoiriano de desmitificar a realidade com a interpretação de comentadoras que veem em suas obras um perfil ético-político e antropológico. Karen Vintges entende que, em $O$ Segundo Sexo, Beauvoir busca captar as "correntes que subjazem o seu tempo", discutindo e integrando os desenvolvimentos sociais e os resultados científicos em uma "visão sintetizadora", como uma tarefa da filosofia social. Para que o "patriarcado" (literalmente, "o governo do pai") não mais prevaleça, mudanças legais e econômicas deverão ocorrer. Contudo, as modificações devem ser radicais, abarcando "instituições, custos, opinião pública e todo o contexto social", para que a igualdade entre mulheres e homens realmente ocorra (Vintges, 2017:14).

Um conjunto de formulações projetam Beauvoir como uma filósofa do século XX, com um complexo pensamento. De um lado, está seu realismo e seu ímpeto à desmitificação, que a fazem 
transitar pela existência munida de certos "parâmetros objetivos" da vida humana, como sexo, nascimento, idade, velhice e morte; de outro, conforme Françoise Rétif (1998), encontra-se um "potencial sempre presente de uma margem de pensamento $e$ ação autônoma, em uma situação que Beauvoir chama de liberdade" (Rétif, 1998:17).

Assentando as preocupações de Beauvoir em bases éticoantropológicas, Debra Bergoffen considera que, entre os tópicos centrais de $O$ Segundo Sexo, destaca-se a atenção pelas instituições humanas que se passam por naturais, que persistem em manter a subordinação das mulheres, entre elas, o casamento (Bergoffen, 2002). Dos acordos dos homens entre si, dos quais as mulheres não são signatárias, o casamento se mostra um conjunto de encargos que delas se exige em todos os tempos e sociedades. A opressão patriarcal qualifica-se de forma institucional como uma ordem social, que se realiza em qualquer sistema econômico (Bergoffen, 2002). Se, para Vintges, o peso econômico-social é crucial no mapeamento do patriarcado, para Bergoffen as instituições patriarcais, especialmente o casamento, ultrapassam limites econômicos e se realçam como estigmas de cada tempo, conforme se projetam nas linhas que se seguem.

Para as comentadoras, a questão da liberdade como princípio maior do existencialismo se choca com os desígnios patriarcais e seus dilemas. Desde os artigos publicados em Les Temps Modernes, transitando pelos escritos dos anos 1940 a 1970, método $e$ bases axiológicas conformam o referencial epistemológico beauvoiriano de dever dizer algo de algum lugar, da ordem de suas escolhas e compromissos com a existência, ressaltando-se sua crítica ao patriarcado ocidental $e$ a suas instituições, aos modos como o casamento e a família foram concebidos historicamente.

O feminino construído e os dilemas culturais em O Segundo Sexo

No processo de desmitificação, algumas questões que fundamentam $O$ Segundo Sexo ganham novos valores ao longo 
de revisões teóricas. Dos anos 1960 em diante, a comunicação com os movimentos feministas toma atenção de Beauvoir e sua autoafirmação como feminista constitui-se de forma ampla, como se lê em suas memórias. Ela se corresponde com militantes feministas norte-americanas que tomavam $O$ Segundo Sexo como obra inspiradora já no final dos anos 1960:

Que a mulher seja fabricada pela civilização (Que la femme soit fabriquée par la civilization), e não biologicamente determinada é um ponto que nenhuma feminista coloca em dúvida (ne met en doute). Elas se afastam de meu livro no plano prático: recusam-se a confiar no futuro, querem desde já dirigir seus destinos. Foi nesse ponto que mudei: dou-lhes razão (je leur donne raison) (Beauvoir, TCF 1972:504; BF1982:493).

Embora a própria Beauvoir não tome seu ensaio de 1949 como um livro militante, suas leitoras e comentadoras já ressaltam a visão de vanguarda estampada em teses e categorias nele manifestas, que abrem horizontes críticos às proposições feministas esboçadas após 1960. Constitui-se assim um universo dialógico com os movimentos feministas, instituindo-se uma certa subjetividade e consciência feminista, tanto para as leitoras e interlocutoras, quanto para a própria Beauvoir.

\section{Leituras possíveis de O Segundo Sexo}

Não se pode desconsiderar o impacto de O Segundo Sexo nos debates prático-teóricos da Segunda Onda do Feminismo, bem como, reciprocamente, no entendimento de Beauvoir sobre o propósito de sua obra. Afinal, as revisões das desigualdades culturais e políticas com relação às mulheres se fundavam, nos anos 1960 e seguintes, na necessidade de compreensão de aspectos de suas vidas pessoais enraizados em questões de ordem política e social, bem como nos efeitos provocados nas instâncias pessoais pelas estruturas de poder. De fato, igualdade ou desigualdade são princípios correlacionais que se projetam em 
função de uma cultura de moldes sexistas. O grande slogan de Carol Hanish (2006), "o pessoal é político" - cujo primeiro manifesto data de 1969 - faz eco às aspirações das mulheres em todo o mundo, em grande parte, leitoras de O Segundo Sexo, especialmente no que se refere às questões de ordem familiar $e$ das relações conjugais.

Sylvie Chaperon (2012) menciona três aspectos principais que sustentam a interlocução entre $O$ Segundo Sexo e as linhagens feministas. $\mathrm{O}$ da assimilação (de l'assimilation), próprio dos anos 1960; o de uma primeira clivagem entendida como recusa de uma natureza feminina (son refus d'une nature féminine), a partir das abordagens feministas na metade dos anos 1960; e uma segunda fratura provocada pelas posições tomadas pelos movimentos de liberação da mulher nos anos de 1970, com a participação nos movimentos e na revisão de princípios pela própria Beauvoir (Chaperon, 2012). Recepção e novas abordagens metodológicas tomam $O$ Segundo Sexo como palco de conquistas teóricas e práticas de liberação e de igualdade, em ações de mulheres que protagonizam suas próprias vidas e seus contextos sociais e políticos.

Os dilemas institucionais do casamento

A dimensão teórica e política da recepção da obra de Beauvoir, segundo Michel Kail (2012), evidencia uma articulação entre o singular e o universal, como uma relação entre as questões da feminilidade (féminité) e de humanidade (humanité), e que subjazem às questões de situação das mulheres. Teses que, de certa forma, coadunam com o entendimento de Debra Bergoffen (2012) em suas análises das instituições convencionais e, especialmente, do casamento, como dimensões éticas e eróticas vivenciadas intersubjetivamente, regidas, contudo, pelo Estado, assim como as formulações existenciais daí decorrentes. Em entrevista concedida em 2012, Bergoffen indica duas abordagens relevantes em $O$ Segundo Sexo: a) o problema do casamento como o desígnio tradicional das mulheres; b) a questão da 
opressão feminina e da ordem social que se realiza em qualquer sistema econômico no patriarcado.

De fato, da leitura do primeiro capítulo da segunda parte daquela obra, pode-se aferir um conjunto de descrições sobre aspectos literários, tanto de ficção quanto da literatura psicológica, que possibilitam a Beauvoir problematizar os hábitos do casamento, consoante mudanças históricas e valores das relações conjugais, os quais ela examina com base em princípios existencialistas. Parte do que fora trazido aos leitores no primeiro volume da obra com relação a mitos, história, literatura, papéis desempenhados $e$ seu sentido na singularidade $e$ na universalidade das relações entre os sexos, ela retoma no segundo volume, com ênfase nas situações vividas por mulheres enquanto crianças, moças, lésbicas, casadas, mães, prostitutas e hetairas, assim como na situação de velhice, entre outras.

O casamento como um ethos convencional no sistema patriarcal

Em O Segundo Sexo, o tema do casamento é abordado sob um prisma de convenção institucional. Contudo, o que Beauvoir utiliza como ponto de partida no segundo volume é bem enfático:

O destino que a sociedade propõe tradicionalmente à mulher é o casamento. Em sua maioria, ainda hoje, as mulheres são casadas, ou o foram, ou se preparam para sêlo, ou sofrem por não o ser. É em relação ao casamento que se define a celibatária, sinta-se ela frustrada, revoltada ou mesmo indiferente ante essa instituição (Beauvoir, SS, v.II, 1980:165).

Observe-se a análise do casamento tanto como fatalidade $e$ sina, bem como meta e objetivo próprios das mulheres, ambos os sentidos baseados em recortes ético-antropológicos. Mesmo que a "condição feminina" apresente modificações em termos econômicos $e$ os hábitos e costumes nas relações conjugais acompanhem o impacto dos tempos, envolvendo maior reciprocidade obrigacional entre os cônjuges $e$ a recepção de 
críticas à suposta "servidão natural" das mulheres, muitas delas ainda se submetem às "antigas estruturas e valores" que regem tal instituição (Beauvoir, 1980). Importa observar o modus operandi da análise de Simone de Beauvoir, para a qual o tema deve sempre receber um tratamento ético, conforme Bergoffen (2012).

$\mathrm{Em} O$ Segundo Sexo questionam-se também os modos pelos quais o casamento patriarcal instrumentaliza seu sentido erótico, usando-o para fins políticos, econômicos, religiosos $e$ culturais, enquanto algo que se corrompe, que vai ganhando feições perversas e de dominação. A dimensão ética torna-se algo alienante do sentido que relações íntimas entre um homem e uma mulher poderiam ter, abolindo paixão e desejo, na forma de controle patriarcal da liberdade feminina. Ainda, "o princípio do casamento" torna-se obsceno, na medida em que "transforma em direitos e deveres uma troca" que deve se basear num "impulso espontâneo" (Beauvoir, 1980:191).

Nesse sentido, o casamento instrumentaliza os corpos, fazendo incidir sobre eles uma força degradante. $\mathrm{O}$ marido parece "cumprir um dever", enquanto a mulher "tem vergonha de se sentir entregue a alguém que exerce um direito sobre ela" (Beauvoir, 1980:191). Beauvoir toca numa delicada dimensão ética da convivência erótica que se estabelece no casamento. Contudo, se o erótico revela mulheres e homens uns perante os outros em sua corpórea e finita ambiguidade, o que ela demonstra é a impossibilidade de se manterem fixas as posições patriarcais, não sendo por acaso que o casamento corrompe o ethos do erótico.

Ademais, o patriarcado protege-se da ameaça erótica em nome da ordem social, descartando-a como irracional e marginal, como se essa dimensão não devesse ser levada a sério. Como única maneira eticamente legítima de expressar o desejo sexual, o casamento legitima a perversão do erótico, confirmando certa institucionalização de condutas humanas, por meio das quais as subjetividades patriarcais seguem as supostas leis imutáveis da natureza. 
A crítica ao naturalismo essencialista das relações humanas

A crítica de Beauvoir ao casamento é também um exemplo de sua desaprovação às reivindicações naturalistas. Ela aponta como a cultura ocidental sempre foi condicionada por estruturas que fixam dualismos intransponíveis. A famosa sentença de abertura do segundo volume de O Segundo sexo, "não se nasce mulher, torna-se mulher", leva-a a uma complexa interlocução temporalizada para além das margens fixas do biologismo determinista. Seu intento específico era, sobretudo, desvincular os indivíduos marcados como "mulheres" de sua condição sexual biológica. Ela já alertava para a necessária investigação da situação do corpo vivido de distintas perspectivas de análise, conforme entendimento, entre outros, de Sara Heinämaa (2002).

Ao tentar desmistificar o, tal como o descreve em entrevista a Jeanson, em 1966, Beauvoir toma como tarefa explorar, em bases fenomenológicas, o processo de mitificação da mulher, destacando que nada há de natural na sua condição, mas um longo e histórico processo de naturalização construído pela civilização. Sua rejeição a todo biologismo leva-a a recusar precisamente que hormônios ou misteriosos instintos possam definir as mulheres ou ditar seus modos de vida. O que conta são os contextos e situações em que as mulheres se encontram, que permitem ou proíbem que corpos vividos possam se relacionar autenticamente com o mundo. Nos termos de Beauvoir, em seus estudos sobre a biologia, ao tratar de certa hierarquia natural de valores, confunde-se um "vago naturalismo" com "uma ética ou com uma estética ainda mais vagas", e que são puro devaneio: "É somente dentro de uma perspectiva humana que se pode comparar o macho e a fêmea dentro da espécie humana" (Beauvoir, 1980:54). Percebe-se assim um projeto crítico de construção social da feminilidade, que passa necessariamente pela "fabricação dos corpos femininos", conforme entendimento de Lamoureux (2002).

Contudo, observo que a proposta beauvoiriana não parece ser a de substituição de um paradigma explicativo - naturalista ou 
essencialista - por outro - antinaturalista e existencialista. Suas exigências epistemológicas orientam seu pensamento para os fenômenos sexualizados e sob o peso da história. Se também "a natureza é uma convenção", como proclama Michel Kail (2002:36), o que ressalta nas questões do casamento presentes em O Segundo Sexo são complexas análises de sua dimensão éticoerótica e de domínio político-social, desvinculando o tema de atribuições naturais e conferindo-lhe tratamento de uma perspectiva histórica e cultural.

Segundo a interpretação de Bergoffen (2012), o postulado existencialista de que "a existência precede a essência" é central para a ideia de que os seres humanos são seres históricos e não naturalmente dispostos no mundo. Ser humano é ser não natural, se por natural se entende ser determinado por uma essência que estrutura nossas vidas. Ao considerar que os seres humanos são fundamentalmente históricos, Beauvoir argumenta sermos seres livres e em transformação e essa é a singular condição da humanidade, embora a liberdade não se realize de modo absoluto, mas esteja sempre situada, tal ideia implicando uma ética de responsabilidades, conforme se apreende em Por uma moral da ambiguidade (1947). Noutros termos, os indivíduos humanos se obrigam a transformar as condições que impedem $e$ que estimulam a liberdade, e a cada momento da vida a dimensão ética se constitui e de forma diferenciada.

Especialmente em $O$ Segundo Sexo, Beauvoir se refere às condições concretas das mulheres na Europa após a Segunda Guerra Mundial, as quais mudaram a própria situação do casamento. À medida que mais mulheres se tornam economicamente independentes, o casamento não é mais tomado como necessário para a sua sobrevivência. As novas condições econômicas têm o potencial de transformar o casamento de um relacionamento que subordina uma esposa a um marido, o qual afirma o seu papel como provedor e protetor, com direitos absolutos sobre o corpo sexual feminino e seus poderes reprodutivos, em uma instituição na qual a diferença sexual é vivida de maneiras que incorporam a natureza ética dos desejos 
sexuais. Ainda no primeiro volume da obra, na terceira parte sobre mitos, Beauvoir comenta que,

quando a mulher é entregue ao homem como um bem, o que ele reclama é que nela a carne esteja presente em sua pura facticidade. Seu corpo não é tomado como a irradiação de uma subjetividade, mas sim como uma coisa empastelada em sua imanência; esse corpo não deve lembrar o resto do mundo, não deve ser promessa de outra coisa senão de si mesmo: precisa deter o desejo (Beauvoir, 1980:200).

Se o domínio histórico ainda é também o domínio naturalizado do corpo feminino tomado como um objeto, segundo Bergoffen (2012), as relações do casamento expõem características de perversão, em que se reforçam as ideologias patriarcais que utilizam o corpo das mulheres como procriativos, objeto de domínio marital.

O lugar institucional de relevo político social

Beauvoir problematiza essa instituição enquanto um costume cultural, que estabelece laços éticos em relação a vínculos eróticos. Ela não sugere que o casamento seja o lugar desejável para a realização dessa ética, mas evidencia a intersecção entre o ético e o político. Entretanto, não parece razoável acreditar que ela possa estar ali impondo sua escolha (de não se casar) às outras mulheres, ou incitando à simples recusa ou crítica institucional. A questão que permanece é até que ponto o patriarcado se impõe a tais compromissos éticos e em que sentido corpos atentos às determinações institucionais são ainda corpos livres que se desejam reciprocamente. Beauvoir escreve que, em termos de "vida ética", absolutamente "não se trata (...) para a mulher de basear em sua singularidade relações com um esposo de eleição, mas sim de justificar em sua generalidade o exercício de suas funções femininas" (Beauvoir, 1980:176). 
Em interlocução com as interpretações de Karen Vintges (2017), pode-se ler em $O$ Segundo Sexo como o patriarcado pode portar muitas dimensões, comparáveis à imagem de um monstro de muitas cabeças, com uma "cabeça" legal, ao lado de uma moral, outra econômica, institucional e social, cada uma representando práticas que deveriam ser substituídas por outras práticas sociais. Para se pensar em mudanças das posições das mulheres nesse sistema, é preciso tomar o patriarcado como uma "verdadeira hidra": ao se cortar uma das cabeças, outras tantas parecem nascer e em domínios diferenciados. A imagem da sociedade como um monstro de muitas cabeças não apenas captura o caráter multifacetado dos padrões patriarcais, como também mostra que diferentes "cabeças" do monstro podem dominar em distintos cenários, "exigindo variadas estratégias de ataque e novos compromissos éticos" (Vintges, 2017:12), assim como práticas de liberdade (freedom practices) para os feminismos contemporâneos, pelas quais se identifiquem projetos éticos $e$ criativos de vida (Vintges, 2017).

O olhar de ironia como método de sustentação crítica

Na segunda parte do ensaio de 1949, na seção nomeada como "Situação", realçam-se os vários contextos em que se encontra "a mulher casada". Logicamente, as amarras institucionais ali se explicitam, mas a perspectiva de Beauvoir parece bem objetiva: a de examinar o lugar ocupado pelas mulheres nas distintas situações, em papéis específicos, nos limites das relações em que sexualidade, feminilidade, direitos e deveres se conjugam num complexo plano ético-político.

Ao longo desse capítulo, de fato, encontram-se pelo menos três leituras metodológicas de Beauvoir, sempre em moldes existencialistas, acerca das condições da "mulher casada". Em primeiro lugar, da perspectiva da literatura, com base nas ficções, dentre outras, de Colette, que tratam em geral das "cínicas experiências" de jovens recém-casadas até a passagem à volúpia conjugal (Beauvoir, 1980:182), ou mesmo nos relatos daquela 
autora sobre o "mistério animal do grande leito fechado", revelando os contrastes do "lado cômico e licencioso do casamento" (Beauvoir, 1980:185); de Honoré de Balzac, em sua igualmente cínica "ciência do casamento" (Beauvoir, 1980:180), na qual o interesse do marido é não ser enganado, algo mais importante do que ser amado; de diversos romancistas $e$ dramaturgos do final do século XIX, como Stendhal, Porto-Riche, Paul Hervieu, Marcel Prévost e Martin Maurice, todos eles em suas descrições sobre as situações ambíguas vividas no casamento, como, para Maurice, as de uma jovem mulher que, após "breve incursão no leito de um amante hábil", retorna ao marido levando os "benefícios" de suas experiências (Beauvoir, 1980:183).

Em segundo lugar, da perspectiva da ficção que se entremeia às memórias filosóficas, trata ela de certo "cinismo" em Montaigne, para o qual o prazer que se tira do casamento deve ser "um prazer contido, sério e acrescido de alguma austeridade", com certa "volúpia absolutamente prudente e conscienciosa", em bom estilo aristotélico (Beauvoir, 1980:178), bem como do que diz Kierkegaard, na sua elucidação do mistério paradoxal dessa estranha invenção que é o casamento (Beauvoir, 1980:181).

Em terceiro lugar, da perspectiva psicológica, fundamentada especialmente em Wilhelm Stekel, também em Helene Deutsch $e$ em Sigmund Freud, cujas análises se voltam para as mulheres ingênuas, sem experiência ou informação sexual e muitas vezes abaladas pelas inabilidades maritais, que acabam por provocar frieza $e$ anestesia permanente nas jovens mulheres (Beauvoir, 1980).

Mas sua ironia é sutil, nem sempre percebida como tal e muitas vezes se explicita de forma pitoresca. $\mathrm{Na}$ análise dos exemplos buscados na literatura e na psicologia, ao examinar alguns modelos de mulheres em situações conjugais, constata como algumas jovens "bem educadas demais" não haviam recebido qualquer educação sexual, acabando por descobrir bruscamente o erotismo que as transtornava na situação de conjugalidade. Três citações demonstram esse veio faceto, quando ela examina os casos investigados por Stekel. Num primeiro deles, 
Beauvoir menciona como, no século XIX, uma tal Mme. Adam imaginava ser seu dever "casar-se como um homem que a beijara na boca, pois pensava que era isso a forma acabada da união sexual" (Beauvoir, 1980:185). Ainda sobre Stekel, na obra Estados Nervosos de Angústia, ela busca dois exemplos mais. Um deles, acerca de uma jovem mulher casada que, durante a viagem de núpcias, teria sido "deflorada pelo marido". Beauvoir registra a peculiaridade da situação, temporalmente definida: "ela o tomou por louco e não ousou dizer palavra, pensando estar lidando com um alienado" (Beauvoir, 1980:185). Finalmente, toma o caso de uma moça que se casou com uma outra e com ela viveu durante muito tempo, "sem desconfiar de que não estava na companhia de um homem" (Beauvoir, 1980:185).

Esses relatos podem parecer advindos de um ethos longínquo, que pouco teria a dizer sobre as jovens mulheres do século XXI. Entretanto, alterando-se a singularidade dos exemplos, que versam sobre a questão trabalhada na introdução da obra de 1949, a alteridade feminina, pode-se afirmar que a situação das mulheres como o outro desigual na cultura ainda permanece. Os velhos problemas do poder patriarcal se mantêm ainda hoje, especialmente quando, em momentos de crise política, várias mulheres vão às ruas protestar por um "não" $e$ outras por um "sim" em torno ao emblema da força viril de quem se lança ao poder com bandeiras ditas reveladoras. Beauvoir, em Balanço final, nos auxilia, ao apontar que, "quando duas castas se enfrentam (quand deux castes s'opposent), na menos favorecida encontram-se sempre indivíduos que, por interesses pessoais, aliam-se aos privilegiados" (Beauvoir, 1972:501; 1982:490).

Mas se interesses, amor e hipocrisia vinculam-se historicamente entre si, no transitar de uma década novos contrastes se verificam, impondo-se o impacto do tempo. O texto sobre Brigitte Bardot, de certa ótica interpretativa, oferece uma sequência, em forma de recusas, vetos, críticas e nova base axiológica da dimensão ético-erótica, revista então nas cenas cinematográficas dos anos 1950. 
O impacto da liberação feminina na figura de $\mathrm{BB}$ e a recepção do público

Acerca do ensaio encomendado a Beauvoir pela revista norte-americana Esquire: The Magazine for Men, vários pontos se destacam, como os conceitos de emancipação e de liberdade, sempre em situação, atravessando as noções do feminino fabricado pela cultura, presentes tanto em $O$ Segundo Sexo quanto em Brigitte Bardot e a síndrome de Lolita.

De fato, as indagações sobre o feminino em processo de transformação na sociedade e, sobretudo, sobre as regras morais $e$ sexuais que cingem as convenções a respeito dos papéis a serem desempenhados pelas mulheres em distintas circunstâncias, surgem em ambos os textos como um dos pontos principais a merecer atenção. Não estou afirmando, contudo, que o feminino seja uma condição apenas das mulheres, mas, no contexto das duas obras, os termos manifestam-se como equivalentes, a saber, a suposta característica feminina ou de feminilidade que afeta culturalmente as mulheres, pelas quais elas têm sido reconhecidas como mulheres, de uma perspectiva quase mítica, louvada pela literatura e normas de dever-ser.

"Feminino" é um termo complexo, que surge com conotações diferenciadas, como bem ressalta Dorothy Kaufmann (1986). Ele denota tanto certa tônica de opressão sob a roupagem de um discurso falocêntrico, quanto uma antecipação do que se registra nos anos 1960 como diferença sexual, nas leituras de Cixous e Irigaray (apud Kaufmann, 1986). Será, contudo, graças às leituras de Beauvoir, propostas por Julia Kristeva, que o termo femnino ganhará projeção paradoxal. Beauvoir pensava o feminino enquanto sujeito em sua condição de alteridade e de singularidade, $e$ isso porque ela havia iniciado "demasiado cedo" a defesa da singularidade feminina, quando ainda havia muitas "condições sexuais e econômicas que punham travas à emancipação das mulheres" (Kristeva, apud Kaufmann, 1986:122).

Em ambos os ensaios, tanto no de 1949, quanto no de 1959, pode-se ler, de perspectivas distintas, questões relacionadas com o 
lugar ocupado pelas mulheres, o que as constitui ou as mitifica enquanto tal, como os impasses sob a perspectiva dos dualismos ditos naturais ou culturais, a base axiológica que sustenta a díade "feminino e masculino" no processo civilizatório. Suas delimitações têm dificultado a quebra de velhos paradigmas, sobretudo morais, que justificam o patriarcado historicamente delineado no Ocidente.

O escrito sobre Brigitte Bardot desenvolve perspectivas valorativas já iniciadas em $O$ Segundo Sexo, que passam então a ser lidas sob a tônica persuasiva dos encantos de $\mathrm{BB}$, ou seja, sobre o feminino em novo processo de revisão moral, ética $e$ erótica. A pergunta "quanto vale o corpo feminino"? torna-se uma questão dialógica entre os dois ensaios.

As pontuações textuais

As análises de Beauvoir sobre Brigitte Bardot projetam-se, inicialmente, como um artigo sob encomenda, cuja primeira publicação, em inglês, data de 1959. Outras edições em inglês virão em seguida, a partir de 1960. Entretanto, somente em 1979 é que a editora Gallimard coletará escritos publicados em primeira versão no exterior e os juntará numa edição francesa intitulada Les écrits de Simone de Beauvoir: La vie- L'écriture. Nessa coletânea, o artigo sobre Bardot encontra-se às páginas 363-376. As edições em francês e em inglês não são, contudo, idênticas e as diferenças foram comentadas na tradução brasileira de 2018 (Santos, 2018), com variações que têm em vista a recepção pelo público francês e norte-americano.

Abordarei esse escrito a partir de alguns níveis de leitura, iniciando por sua textualidade, para que o rigor da materialidade que lhe é própria não seja desconsiderado. $\mathrm{Na}$ sua escrita por encomenda, o estilo de Beauvoir é um dado primordial, respondendo à legitimidade de suas intenções e do seu método de pensamento. Isso tem sido objeto de investigação de várias pesquisadoras, especialmente Sylvie Le Bon de Beauvoir (2018), a qual entende que Beauvoir, por meio de uma linguagem 
comunicável, se inscrevia "na urgência histórica" (Le Bon de Beauvoir, 2018:21).

Um segundo nível de leitura é de ordem históricoconceitual. Nesse sentido, importante observar o referencial cultural de uma revista masculina, Esquire: The Magazine for Men, no final da década de 1950. O volume em que se publica o trabalho de Beauvoir divide seu conteúdo (contents) entre artigos (articles), personalidades (personalities), ficção (fiction), suplemento (supplement), viagens (travels), ensaios (essays) vestimentas (wearables), entre outros; Brigitte Bardot e a síndrome de Lolita estando logo na primeira seção, a de artigos, às páginas 32-38 do número de agosto de 1959.

Entende-se, inicialmente, tratar-se de um simples texto com tópicos comparativos sobre a atriz francesa, que se publica numa revista masculina nos EUA, ao lado de dois outros artigos da mesma seção, versando, o primeiro deles, sobre Babe Ruth profissional do baseball norte-americano - $e$ o segundo a respeito da indústria de licores. Contudo, a construção $e$ a apresentação por Beauvoir da atriz Brigitte Bardot, em seus filmes dos anos 1950, não permite que se considere o texto como mero objeto de deleite ou de consumo masculinos, como poderiam ser os dedicados a esporte ou bebidas. Não se pode prejulgar que o leitor da revista se interesse tanto por beisebol, quanto por licores, deparando-se, entre textos a isso dedicados, com a leitura inusitada sobre a atuação cinematográfica da atriz $\mathrm{BB}$, como era então conhecida.

Uma questão que deve ser examinada é por que o ensaio sobre $\mathrm{BB}$ ali se encontra e qual o propósito tanto para a revista, em função de seus destinatários, quanto para Beauvoir, que aceita o desafio da encomenda e escreve sobre a atuação da atriz especialmente em filmes como E Deus criou a mulher, já lançado em novembro de 1956, versando sobre a complexidade humana em meio às inusitadas relações conjugais de dois jovens, ou Amar é minha profissão, estreado em 1958. 
Os efeitos estéticos

O escrito de Beauvoir tem um alcance bem amplo, o que a Estética da Recepção, na linha proposta por Hans-Robert Jauss e Wolfgang Iser, entre outros, chamaria de "gozo estético", remetendo ao terceiro nível de leitura, o hermenêutico, com nuanças profundas em termos de recepção $e$ comunicação com os leitores. De fato, pode-se apreciar o texto em conformidade com os efeitos que produz. Beauvoir escreve sob encomenda, como um encargo a ela confiado pelos editores da revista, para que o seu público leitor possa ter acesso a um assunto atual em sua época, que traz à tona experiências analógicas de duas culturas diferentes, a francesa e a norte-americana - dois públicos distintos, o europeu-conservador e o americano que se volta para o futuro, para o mercado de técnicas e ganho de dinheiro. Nos escritos sob encomenda, os contrastes culturais entre franceses $e$ norteamericanos se registram $e$ as possibilidades de gozo estético se diferenciam. Parece-me que a intenção de Beauvoir é justamente essa, a de cotejar as culturas a pretexto da performance de Brigitte Bardot, investigando de que forma o feminino inscrito corporalmente nos gestos da atriz reproduz as objeções culturais, de forma diferenciada, em ambas as culturas.

Analogias na recepção do escrito

Muito embora seja publicado numa revista norte-americana, o que Beauvoir parece ter em mente é demonstrar as dificuldades do público francês em lidar com o feminino que eclode nas práticas desconcertantes que se registram nos filmes protagonizados por Brigitte Bardot, revelando, outrossim, que, apesar das mudanças culturais, os americanos também rejeitam formas de autonomia feminina, recusando a mulher real, que é tomada por eles como uma "rival, um louva-a-deus e um tirano", justamente por não se prestar a "sublimações idealistas" (Beauvoir, 2018:85). 
Beauvoir indaga, assim, qual o semblante do feminino exposto em $\mathrm{BB}$, que constrange e seduz. O ponto de partida de sua análise é a recepção, pelos franceses, de um programa de televisão em que $\mathrm{BB}$ aparece, considerando-se as condições de comunicação com públicos diferentes, cercada de certa ironia, justamente para demonstrar seu pensamento crítico:

Na noite de ano novo, Brigitte Bardot apareceu na televisão francesa. Estava vestida como sempre - blue jeans, suéter $e$ uma madeixa de cabelo despenteada. Reclinada em um sofá, dedilhava as cordas de um violão. "Isso não é difícil", disseram as mulheres. "Eu poderia fazê-lo tanto quanto ela. Ela nem é bonita". (...) Os homens não podiam se conter em devorá-la com os olhos, mas também zombavam dela. (...) Mais uma vez eu pude observar que Brigitte Bardot não era amada em seu próprio país (Beauvoir, 2018:69).

Seguindo um diagnóstico sobre valores principalmente morais, que acendem de hostilidade leitores e espectadores que não recepcionam facilmente as mudanças dos tempos, em especial, na Europa da década de 1950, Beauvoir tece uma refinada análise sobre hábitos e costumes em que o feminino protagoniza como tema central na figura de $\mathrm{BB}$. Seu método de abordagem é relevante, devendo ser levado em consideração, pois segue com certa similitude a sua estratégia argumentativa habitual, próxima ao que se registra em vários de seus ensaios $e$, especialmente, ao método utilizado em $O$ Segundo Sexo.

Métodos interpretativos

Beauvoir tem por critério metodológico testificar o que pensam e alegam seus concidadãos em certas fases da história do pensamento e dos costumes, ou mesmo as diferenciadas formas de raciocínio presentes na trajetória histórica, sempre em moldes analógicos; visa, outrossim, estabelecer, simultaneamente, um exame próprio em bases críticas da situação investigada. Nesse sentido, nem sempre é façanha simples reconhecer, à primeira 
vista, a linha demarcatória entre o que ela tem a considerar, por um lado, sobre as formas de pensamento alheio e forjadas culturalmente $e$, por outro, suas próprias abordagens interpretativas e valorativas.

No caso específico do ensaio sobre $\mathrm{BB}$, seus parâmetros descritivos, dotados de certo "realismo dialético", tal como o nomeia Sonia Kruks (apud Rétiff, 1999), muitas vezes leva seus leitores a uma avaliação equivocada de seu pensamento, assumindo algo como próprio da filósofa, quando, na verdade, trata-se de um tópico por ela criticado. Pode-se, pois, verificar como as referências a BB são paradoxalmente dispostas. Assim a identifica Simone de Beauvoir: $\mathrm{BB}$ é "o novo ídolo da juventude americana" (Beauvoir, 2018:70), contudo, é também pessoa enfadonha para os franceses; ela é a reinvenção do "eterno feminino" pelo diretor Roger Vadim, que faz surgir um "novo gênero de erotismo" (Beauvoir, 2018:72), seduzindo e chocando seu público, tanto com sua ambiguidade andrógina, quanto com sua feminilidade negligente (Beauvoir, 2018:73); ela demonstra um lado "tradicional da feminilidade" inscrita na cultura, como "a ingenuidade pintada por Vadim", o lado instintivo que segue seus impulsos, que apanha do jovem marido e se sente restabelecida em suas forças naturais, em "suas personagens cheias de clichês" (Beauvoir, 2018:77), contudo, sua forma de atuação "não permite que os filmes caiam na banalidade" (Beauvoir, 2018:78).

Suas apreciações estéticas não versam sobre dualidades ou dicotomias, mas sobre a condição de ambiguidade que habita a singularidade humana, numa mescla de impactos e seduções. Não se pode perder de vista que, embora o trabalho tenha sido publicado sob outras formas na década de 1960 - tanto pelas editoras londrinas Deutsch, Weidenfeld and Nicholson, em 1960, e The English Library, em 1962, quanto por editoras de Nova York, Reynal, 1960 e Arno Press, em 1972 - a primeira edição foi numa revista masculina norte-americana. Pode-se então indagar, qual a expectativa de recepção ou de efeito estético da parte da autora? A ambiguidade nas várias edições poderia ter algum sentido em sua concepção autoral? 
Beauvoir permite aos seus leitores uma percepção do que sabem e pensam os norte-americanos, do que criticam e reprovam os franceses. Nessa reorganização dos campos de referência, expressa-se a intenção comunicativa do texto, que vai ganhando novos sentidos em termos representativos. A cada leitura, em cada publicação, novos campos hermenêuticos se abrem, chegando assim ao nosso próprio momento histórico.

De fato, a interpretação, segundo Wolfgang Iser, somente funciona se o efeito estético, embora causado pelo texto, exigir também a atividade de representar e perceber da parte dos leitores, a fim de que sejam conduzidos a uma diferenciação de atitudes. Um texto não pode ser entendido como algo preexistente, pronto e acabado, senão enquanto reformulação da realidade já manifesta; dessa maneira é que "chega ao mundo algo que não se encontrava nele propriamente" (Iser, 1987:12). Esse é justamente o impacto causado pelos filmes encenados por Brigite Bardot então, gerando inusitadas reações de seu público.

Os ardis de $\mathrm{BB}$

Beauvoir foca nas reações de seus leitores frente às provocações textuais e estéticas que o cinema produz. Afinal, no que poderia interessar a tais leitores-interlocutores norteamericanos um artigo sobre uma atriz francesa, cujos filmes são tomados como bastante exóticos, especialmente em seu país de origem? De forma sutil e analógica, Beauvoir compara $\mathrm{BB}$ às atrizes de seu tempo, como Marlene Dietrich, a vamp com "olhares em chama", que leva os homens para uma "armadilha fatal"; Bardot, demonstra apenas cinismo, com uma "candura que desarma" (Beauvoir, 2018:82); Greta Garbo, "a Divina", com sua "expressão vaga em que se podia projetar qualquer coisa"; no rosto de Bardot "não se pode projetar nada", pois ela parece encurralar os homens $e$ os "força a serem honestos consigo mesmos", reconhecendo a "crueza de seu desejo" (Beauvoir, 2018:86); Katharine Hepburn, especialmente no filme Uma Aventura na África, já envelhecida e demonstrando ali uma 
situação de exaustão, mas ainda estimulando desejo em situação específica; por sua vez, BB "des-situa" a sexualidade, ela expõe sua nudez ao sol apenas como um "corpo anônimo", como em $E$ Deus criou a mulher (Beauvoir, 2018:89), numa combinação indiferente, mas com normas muito particulares e provocativas, sem jamais apelar para a cumplicidade de seu espectador.

$\mathrm{Na}$ interpretação de Beauvoir, as atitudes de BB chocam o público francês em seu moralismo convencional. O diretor, Roger Vadim, singularmente cria uma figura fora das normas previstas do feminino ajustado aos padrões tradicionais e sequer propõe uma "estória convincente", enquanto as personagens são "tratadas por alusão" (Beauvoir, 2018:89). Beauvoir investiga como Bardot protagoniza o feminino que habita "um mundo ausente", apenas com uma sensualidade concentrada, com certa agressividade em sua feminilidade, que atiça escárnio e excitação em seu público. Contudo, entende Beauvoir não se tratar apenas de um projeto de direção estético-cinematográfica, mas do que Bardot realmente demonstra como estilo próprio que torna seu público um "voyeur a contragosto" (Beauvoir, 2018:89).

No entendimento de Beauvoir, a atriz parece capturar o espectador, mas seus filmes provocam "protestos violentos", pois são tomados como verdadeiros ataques à ordem social. Brigitte não precisa fingir para seduzir, ela "não transige jamais com o que lhe parece uma evidência" e sua autenticidade é bem contagiosa (Beauvoir, 2018). Suas personagens trazem ao cinema um significado subversivo, numa mescla de pureza e sedução. Decerto, um perfil do feminino para além das possibilidades de seu tempo, ultrapassando limites de imposição e referendando-se em novas bases axiológicas.

No filme E Deus criou a mulher, a cena do jantar do casamento merece ser investigada em comparação com os aspectos analisados anteriormente. Na descrição de Beauvoir,

Juliette imediatamente vai para a cama com seu jovem marido. No meio do banquete, ela repentinamente aparece num robe de chambre e, sem se incomodar em sorrir ou 
sequer olhar para os convidados aturdidos, pega, de baixo de seus narizes, uma lagosta, um pedaço de frango, frutas $e$ garrafas de vinho. Desdenhosa, vai embora tranquilamente com a sua bandeja. Não dá a mínima para opinião alheia. BB não tenta escandalizar. Não exige nada (...) Segue suas inclinações. Come quando tem fome e faz amor com a mesma simplicidade. $\mathrm{O}$ desejo e o prazer parecem-lhe mais verdadeiros do que os preceitos e as convenções.(...) Faz o que lhe agrada, e é isso que é perturbador (Beauvoir, 1980:79).

Em $O$ Segundo Sexo, considerando as vivências matrimoniais descritas por Stekel, Beauvoir alude aos modos de satisfação sexual, com o uso frequente de fantasias eróticas, de criação de "transposições grotescas e inversões", como "comédias representadas entre parceiros" que ameaçam destruir toda "fronteira entre a aparência e a realidade". Nos limites extremos dos casamentos analisados por Stekel, "vícios definidos aparecem". E o vício assume um "aspecto organizado e frio, um aspecto sério que faz dele o mais triste mal menor" (Beauvoir, 1980:193).

Já no filme encenado por $\mathrm{BB}$, a suposta frieza com que a implícita relação sexual dos recém-casados é retratada torna-se ironicamente reinventada, em vista dos constrangimentos que causa no público. Afinal, escreve Beauvoir, "as faltas morais podem ser corrigidas, mas como $\mathrm{BB}$ poderia ser curada dessa deslumbrante virtude: a autenticidade?" (Beauvoir, 1980:80).

Os antagonismos da sedução

Os contrates então se expressam: por um lado, os espectadores franceses manifestam na recepção dos filmes, nas críticas e formas de reação o que esperam de uma mulher no final da década de 1950, deparando-se, contudo, com uma personagem absolutamente livre em seus trajes, sem maquiagem $e$ joias, em cenas de total incitamento. Já os americanos, embora não tenham o gosto, como os franceses, "pela licenciosidade" $e$ 
tenham tendência a mostrar algum respeito pelas mulheres, já se tendo, inclusive, reconhecido certa "igualdade sexual" nos EUA, também demonstram "certa antipatia pela "mulher autêntica" (Beauvoir, 2018:83). Na França, escreve Beauvoir, os homens parecem preferir o "servilismo" das mulheres à "imprudência altiva" de Bardot" (Beauvoir, 2018:86), já que ela desconcerta na medida em que desencoraja familiaridades e não se presta tampouco a sublimações idealistas.

No efeito estético que se descobre, Beauvoir apresenta com sutileza o feminino, que não mais disfarça a sua liberdade de expressão. Bardot inaugura algo não convencional. Nada parece mais realista e com impacto de desmitificação do que o lugar que um semblante feminino autêntico e original, independente e com exigências de simetria de gênero, nas páginas de uma revista masculina. Não se trata de um objeto de consumo, mas de um sujeito que protagoniza sua liberdade e não a condiciona ao universo masculino.

As edições posteriores do escrito demonstram sua vitalidade, apesar das mudanças que parecem se operar nos filmes de $\mathrm{BB}$ ao longo dos anos. A expectativa de Beauvoir é que Brigitte não mude ao ponto de ferir uma proposta inovadora. Ferir uma figura revolucionária e livre que tornou possível ao mito do "eterno feminino" se desnudar diante das telas cinematográficas. BB é a própria revolução feminina que rompe inclusive com paradigmas de bem e de mal estabelecidos na sociedade patriarcal. Afinal, entende Laura Piccioni, no escrito de Beauvoir, $\mathrm{BB}$ destaca características como "erotismo e sexualidade em simetria com seus parceiros" (Piccioni, 2012:225), sem deles depender ou sem demonstrar necessidade de reconhecimento de direitos, sem voltar-se para uma fixação aos padrões de moralidade. Ela parece romper com os tabus da moralidade burguesa e se representa como a figura do "feminino emancipado" (Piccioni, 2012:225), descurada de preocupações pelo reconhecimento tanto masculino quanto social.

Na descrição de Beauvoir, o que se demonstra é um ethos do erótico que não se prende a formalidades de regulação. Afinal, 
em seu descaso pelas normas de recato de uma moça recémcasada, por exemplo, Bardot desconsidera as delimitações morais pelas quais o feminino então se conduzia. Por outro lado, Beauvoir percebe que o público francês espera dela uma certa recuperação moral, que se case, que tenha filhos, que retorne ao ethos tradicional de uma moralidade que foi por ela rompida $e$ inovada. Decerto, o que o público anseia, no final dos anos 1950, é que o feminino inovador de $\mathrm{BB}$, liberado das correntes do cinismo moralista de sua época, não se mantenha em vestes revolucionárias, nem abra novos espaços sociais ou sexuais, ficando sob a rédeas patriarcais.

\section{Conclusão}

Simone de Beauvoir, em seu processo de desmitificar o lugar sagrado e reservado às mulheres no processo civilizatório, critica formulações arbitrárias e certas intervenções no mundo $e$ nas estruturas sociais dominantes, ensejando nos leitores atividades de representação e percepção que os conduzem a atitudes interpretativas próprias. O texto é o referencial, mas é preciso que seja um texto aberto, com lacunas a serem preenchidas pelo exercício da leitura. Esse é o pacto de leitura que Beauvoir propõe, um "apelo à liberdade" que se apresenta na espessura e na riqueza ambígua de um mundo, como ela propõe, em 1956, em Literatura e Metafísica.

Na forma inaugural, crítica e até paradoxal de seus escritos pois tanto ela dá sequência à tradição filosófica, quanto com ela simultaneamente parece romper -, com seu método de seguir e de contestar, de retomar e de comentar, Beauvoir apresenta uma forma própria de filosofar e de tornar a filosofia uma prática dialógica de vida. Tanto em $O$ Segundo Sexo, quanto em Brigitte Bardot e a síndrome de Lolita, o diálogo com a ambiguidade da existência sustenta correlações temáticas, tomando o vínculo com o feminismo contemporâneo um movimento contínuo da hermenêutica beauvoiriana. 
Não se pode esquecer que Beauvoir teria conduzido o feminismo à condição de um tema filosófico e antropológico, o que lhe teria valido imensas críticas, mas, certamente, também provocado grande adesão da parte de suas leitoras durante pelo menos setenta anos após a publicação de seu primeiro ensaio sobre sexo, gênero e cultura, sob o irônico título de um "segundo sexo".

\section{Referências bibliográficas}

BEAUVOIR, Simone de. Brigitte Bardot e a síndrome de Lolita e outros escritos. Belo Horizonte, Quixote + Do editores, 2018. Tradução, organização e notas de Magda Guadalupe dos Santos e Paulo Sartori. [1959]

BEAUVOIR, Simone de. Brigitte Bardot and the Lolita Syndrome. Esquire. The Magazine for Men. Chicago, n.19, August, 1959, pp.32-38. Tradução de Bernard Fretchman.

BEAUVOIR, Simone de. Brigitte Bardot and the Lolita Syndrome. Londres, The New English Library Ltd, 1960. Tradução de Bernard Fretchman. [1959]

BEAUVOIR, Simone de. Tout compte fait. Paris, Gallimard, 1972 (exemplaire de l'édition originale).

BEAUVorR, Simone de. Le Deuxième sexe. Paris, Gallimard, 1976 (Folio). [1949]

BEAUVOIR, Simone de. Brigitte Bardot et la syndrome de Lolita. In: FRANCIS, Claude: GonTIER, Fernande (org.). Les Écrits de Simone de Beauvoir. La vie, L'écriture. Paris, Gallimard, 1979, pp.363-376.

BEaUvolR, Simone de. O Segundo sexo. vol. I. Fatos e Mitos. Rio de Janeiro, Nova Fronteira, 1980. Tradução de Sérgio Milliet. [1949]

BEAUVorR, Simone de. O Segundo sexo, vol. II. A experiência vivida Rio de Janeiro, Nova Fronteira, 1980. Tradução de Sérgio Milliet. [1949]

BEAUvoIR, Simone de. Balanço Final. 3.ed. Rio de Janeiro, Nova Fronteira, 1982. Tradução de Rita Braga. [1972] 
BEAUVOIR, Simone de. Literatura e Metafísica. In: BEAUVOIR, Simone de. $O$ existencialismo e a sabedoria das nações. 4. Ed. Lisboa, Esfera do Caos, 2008. pp. 65-75. Apresentação de Michel Kail. Tradução de Mário Matos. [1948]

BERGOFFEn, Debra. Le marriage commme promesse. In: DELPHY, Christine; CHAPERON, Sylvie. Cinquantenaire du Deuxième sexe. Paris, Syllepse, 2002, pp.246-258. (Nouvelles Questions féministes).

Bergoffen, Debra. Interview. Sapere Aude, vol. 3, n. 6, Belo Horizonte, $2^{\circ} \quad$ semestre 2012, pp.366-378 [http://periodicos.pucminas.br/index.php/SapereAude/article/view/473 9/5005 - 18 abr. 2019].

CHAPERON, Sylvie. Beauvoir et le féminisme français. In: LECARMETABONE, Éliane; JEANNELLE, Jean-Louis (org.). Le Cahier de L'Herne. Paris, L'Herne, 2012, pp.277-283.

FEMENíAs, María Luisa. Sobre sujeto y género. (Re) Lecturas feministas desde Beauvoir a Butler. 2. ed. Rosário, Prohistoria, 2012.

HANISCH, Carol. The Personal is Political. 2006 [1969] [http://www.carolhanisch.org/CHwritings/PIP.html - acesso em 18 abr. 2019].

HEINÄMAA, Sara. Les sources phénoménologiques: le corps vécu et ses expressions, In: DELPHY, Christine; CHAPERON, Sylvie. Cinquantenaire du Deuxième sexe. Paris, Syllepse, 2002, pp.48-55. (Nouvelles Questions féministes).

ISER, Wolgang. El acto de ler. Teoría del efecto estético. Madrid, Taurus, 1987. Tradução de J. A. Gimbernat. [1976]

JEANSON, Francis. Deux entretiens de Simone de Beauvoir avec Francis Jeanson. In: JEANSON, F. Simone de Beauvoir ou l'enterpreise de vivre. Paris, Seuil, 1966, pp.251-256.

KAIL, Michel. Simone de Beauvoir philosophe. Paris, Presses Universitaires de France, 2006.

KAIL, Michel. De la féminité à l'humanité. In: LECARME-TABONE, Éliane; JEANNELLE, Jean-Louis (org.). Le Cahier de L'Herne. Paris, L'Herne, 2012, pp.271-276. 
KAUFMANN, Dorothy. Simone de Beauvoir: Questions of Difference and Generation. Yale French Studies, n.72, Simone de Beauvoir: Witness to a Century, 1986, pp.121-131.

LAMOUREUX, Diane. Le paradoxe du corps chez Simone de Beauvoir. In: DelPhy, Christine; ChAPERON, Sylvie. Cinquantenaire du Deuxième sexe. Paris, Syllepse, 2002, pp.56-63. (Nouvelles Questions féministes).

Le Bon De Beauvoir, Sylvie. Apresentação. Por que ler Simone de Beauvoir hoje? Pourquoi lire Simone de Beauvoir aujourd'hui. In: BEAUVOIR, Simone de. Brigitte Bardot e a síndrome de Lolita e outros escritos. Belo Horizonte, Quixote + Do editores, 2018, pp.17-40. Tradução, organização e notas de Magda Guadalupe dos Santos e Paulo Sartori.

PICCIONI, Laura. Les artifices de B.B. selon Simone de Beauvoir. Sapere Aude, Belo Horizonte, vol.3, n.6, $2^{\circ}$ sem. 2012, pp.224-233 [http://periodicos.pucminas.br/index.php/SapereAude/article/view/478 3/4993 - acesso em 23 mar. 2019].

RÉTIF, Françoise. Simone de Beauvoir. L'autre em miroir. Paris, L'Harmattan, 1998 (Bibliothéque du féminisme).

SANTOS, Magda Guadalupe dos. Beauvoir: paradoxos e interlocuções metodológicas, Sapere Aude, Belo Horizonte, vol.3, n.6, $2^{\circ}$ sem. 2012 , pp.

271-297 [http://periodicos.pucminas.br/index.php/SapereAude/article/view/472 8/4996 - acesso em 23 mar. 2019].

VINTGES, Karen. La réponse adéquate de Beauvoir à la question "Qui sommes-nous aujourd'hui?" In: DELPHY, Christine; CHAPERON, Sylvie. Cinquantenaire du Deuxième sexe. Paris, Syllepse, 2002, pp.152156. (Nouvelles Questions féministes).

VINTGES, Karen. A New Dawn for the Second Sex: Women's Freedom Practices in World Perspective. Amsterdam, Amsterdam University Press, 2017. 